\title{
SPATIAL-TEMPORAL CHANGES OF LAND DEGRADATION CAUSED BY NATURAL AND HUMAN INDUCED FACTORS: CASE STUDY OF BULGAN PROVINCE IN CENTRAL MONGOLIA
}

\author{
Sainbayar Dalantai ${ }^{1,2}$, Erdenesukh Sumiya ${ }^{2, *}$, Yuhai Bao ${ }^{3}$, Munkhdulam Otgonbayar ${ }^{1,2}$, Urtnasan Mandakh $^{1}$, \\ Bayartungalag Batsaikhan ${ }^{1}$, Boldbaatar Natsagdorj ${ }^{1}$

\begin{abstract}
${ }_{1}$ Institute of Geography and Geoecology, Mongolian Academy of Sciences, Ulaanbaatar 15170, Mongolia - (sainbayard, munkhdulamo, urtnasanm, bayartungalag_b, boldbaatarn)@mas.ac.mn
\end{abstract} \\ ${ }^{2}$ School of Arts and Sciences, National University of Mongolia, Ulaanbaatar 14201, Mongolia - erdenesukh@ num.edu.mn \\ ${ }^{3}$ College of Geographical Science, Inner Mongolia Normal University, Hohhot 010022, China - baoyuhai@imnu.edu.cn
}

Commission TCIV, IV/3

KEY WORDS: Central agriculture region, Aridity index, Land degradation.

\begin{abstract}
:
Land degradation and desertification have been ranked as a major environmental issue for arid and semi-arid regions is a comprehensive concept that depends on many factors. Detecting early land degradation is a significant issue of social and environmental with geographical information system (GIS) and remote sensing methods has been used for the interpretation of spatial-temporal data. In this study, the assessment of the current state of land degradation is influenced by several complexes of the natural and anthropological causes. The results of land degradation assessment carried out for Bulgan province of Mongolia using multi-temporal resourced data as climate condition (vegetation growing season of temperature and precipitation), land use type (density of seasonal camps of herder households, roads, cropland, settlements) and MODIS vegetation product data were used to estimate land degradation change period from 2000 to 2018 and accessed it's for effecting on degradation over last 19 years. We obtained a prediction of land degradation integrated with indicators and based on the spatial pattern of human influence. One of the main indicators for land degradation was land use type as pasture usage of livestock husbandry in Bulgan province, overgrazing is the most widespread cause of land degradation, particularly around permanent location of herders and livestock affecting about moderately and slightly degraded land is $72.78 \%$ of study total area.
\end{abstract}

\section{INTRODUCTION}

Desertification is a defined as land degradation in arid, semi-arid, and dry sub-humid areas resulting from many factors such as climate change and human activities by United Nations Convention to Combat Desertification (UNCCD) (Nachtergaele et al. 2008; Spruce et al. 2011). Between 2012 and 2016, degraded land covered approximately $19 \%$ of the global land area (Kimura, 2018).

Land degradation and desertification mean which is a process loss of terrestrial ecosystem or declining biological productivity (METM, 2014). In other words, it means the loss of ecosystems or the population of living organisms and their habitats. It occurs as a result of changes in dynamic processes such as climate (drought, increase in extreme phenomena of climatic elements), hydrology (decline in groundwater level), soil (soil salinization), vegetation (loss of vegetation cover), and biodiversity (species decrease or extinction) (Dash, 2010). The combination of natural factors and human activities are intensifying the process of land degradation and leading to create for desertification. When land degradation occurs in dryland, it often creates desert-like conditions (Sterk and Stoorvogel, 2020) due to lack of moisture supply, limited rainfall, and significant fluctuation of the seasonal temperature. Therefore, areas with arid, semi-arid, and lack of moisture are more sensitive to natural and human impacts. Ultimately it leads to poverty and malnutrition due to economic slowdown followed by a decline in biological production.
Many scientists have conducted an assessing land degradation at the national and local level, using determined indicators under the program for Land Degradation Assessment in Drylands (LADA) by the Food and Agriculture Organization (FAO) of the United Nations. In Mongolia, many researchers have investigated of drought and desertification (METM, 2014; Dash, 2010; NPCDM, 2010; Dorjgotov, 2009; Natsagdorj, 2009; IGB\&IG, 2014; Tsogtbaatar and Khudulmur, 2014). For instance, Mandakh et al (2015) determined using the numeric index of desertification map that $77.8 \%$ of the total territory was affected by land degradation. They reported natural factors were plays $56.0 \%$ and human activity factors in $44.0 \%$ in a strong and very strong deserted area. Natsagdorj, Dulamsuren, and Tsatsral (2009) also have conducted extensive research on desertification from the perspective of climatic factors. Dash (2010) noted that the area of the desert zone has increased by $3.4 \%$ due to changes in the normalized vegetation difference index (NDVI) over the past 10 years. Multi-years average NDVI has widely used in desertification and land degradation study in Mongolia (Munkhdulam and Sainbayar, 2012).

An integrated process that depends on many factors, also the continuity and accuracy of data are vital in land degradation studies. The data provides the requirements, is obtained from Earth Observation (EO) or a global observing system based on remote sensing technology. In the land degradation study, NDVI is widely used and more suitable (Higginbottom and Symeonakis, 2014). Vegetation cover does not only contribute to the accumulation of organic matter in the soil but also employs a

\footnotetext{
* Corresponding author
} 
mechanical effect on the soil generation process. Therefore, changes in vegetation cover affect soil degradation and erosion. The FAO/LADA technical report also states that the NDVI is an indicator of land degradation (Kellner et al, 2011) that is interdependent to precipitation change, drought index, land cover change, and soil erosion. Therefore, climate change and human activities are the main reason for vegetation change. Many researchers have investigated land degradation and desertification based on long-term NDVI data derived from MODIS satellite, have detected a trend using slope value of linear regression (Bai and Dent 2006; Higginbottom and Symeonakis, 2014; Natsagdorj, 2009).

The integrated assessment of land degradation is based on four categories by degradation detection: slight, moderate, severe, and very severe (Dash, 2010). Human-induced and climate factors still have separate issues, which is the main challenge to determine and mitigate land degradation effectively (Evans and Geerken, 2004). The aim of this research is to assess the impacts of natural and human factors and develop a spatial model of regions exposed to land degradation and desertification.

\section{STUDY AREA}

Bulgan province is located, at an altitude ranging from $950 \mathrm{~m}$ to $2000 \mathrm{~m}$ above sea level, in the northern part of Mongolia, it covers $488.733 \mathrm{~km}^{2}$, which is $0.3 \%$ of the entirety of Mongolia (Figure $1)$.

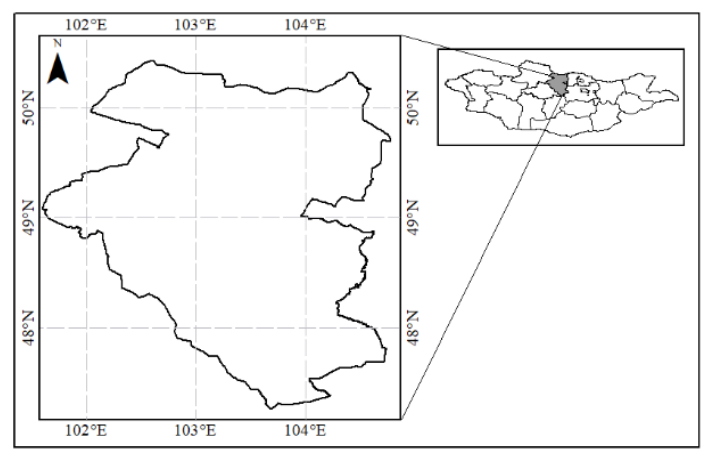

Figure 1. Location map of study area.

The province is divided into administrative subdivisions of 16 soums and 75 bags, and has a population of 61.794 and livestock of 3.305 .495 as of 2018 . For the natural zone, mountain taiga, mountain forest-steppe, and moderate dry steppe zones include, which are stretched from the north into the southern part (NPCDM, 2010). In this study area, pasture vegetation and soil surveys were conducted in 2005 and 2014 (IGB\&IG, 2014). According to the report of this study:

- Field studies of pasture vegetation indicate that the average biomass of public pasture land has decreased to $440 \mathrm{~kg} \mathrm{ha}^{-1}$ in 2014 , whereas it was $1010.0 \mathrm{~kg} \mathrm{ha}^{-1}$ in 2005 .

- The soil survey shows that soil humus content ranged between $0.737-2.835 \%$ in the brown and dark brown sandy loam soil of flat land zone and $0.352-2.193 \%$ in the alluvial sandy loam soil of river valley, where enduring erosion and deterioration caused by human activities and overgrazing, and land degradation rate is higher in such areas including the vicinity of soum center and the places of open water resources.

- In some areas, soil fertility capability has worsened due to the expansion of sand buried soil, triggering sand accumulation in the settlement areas.
- $\quad$ Abandoned crop fields encourage the growth of weed and the spread of its seed into the pasture land, and this causes the degradation of pastureland vegetation.

- A certain extent of soil erosion was detected in the pastureland near the settled areas and places of 1.0 to $3.0 \mathrm{~km}$ range around open water source spots due to livestock watering.

- This report has confirmed that the territory of Bulgan province is experiencing degradation, and such intensely degrading land is highly vulnerable to the risk of desertification. Above mentioned risks have become the ground for choosing the area as a subject of this study. Therefore, the risk is the rational basis for the site selection of this study.

\section{METHOD AND MATERIALS}

\subsection{Materials}

Climate data: Mean air temperature and total precipitation data of June, July, and August of 2000-2018, obtained from 60 meteorological observation stations, evenly located across Mongolia's territory, were used in the calculation of the aridity index. The meteorological precipitation data used in spatial distribution analysis of Rainfall-Use Efficiency (RUE). Firstly, we have generated spatial distribution images of temperature and precipitation using the kriging interpolation method from 60 meteorological station data of June, July, and August of 20002018. The temperature and precipitation images of the study area were extracted from the full image.

In order to detect the change of time-series and the trend, we were estimated Sen's slope value of the temperature and precipitation in the warm season. The detail method is found from Chattopadhyay's study (Chattopadhyay et al, 2016). The Sen's slope is a non-parametric test, and the non-parametric method does not require normally distributed (Chattopadhyay et al, 2016; Touseef et al, 2020; Otgonbayar et al, 2019a). The natural phenomena are often un-normal distributed. Therefore, Sen's slope test might be more suitable (Otgonbayar et al, 2019b). The analysis showed that over the past 19 years, yearly average air temperature less slightly decreased, and the yearly total precipitation increased, at the Bulgan meteorological station (Figure 2).

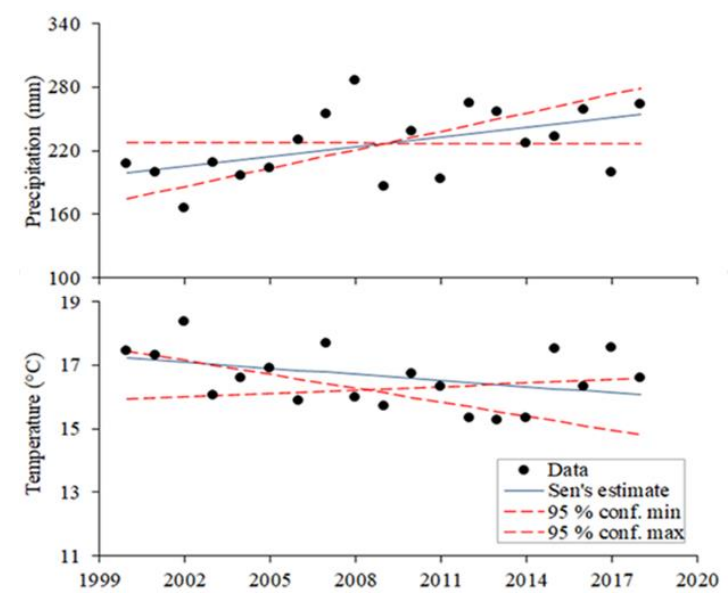

Figure 2. Yearly average temperature and yearly total precipitation for the period 2000-2018 (from June to August) at the Bulgan station with Sen's slope estimate (95\% confidence intervals).

Normalized difference vegetation index (NDVI): NDVI data, which is MOD12A3 derived from Moderate Resolution Imaging 
Spectroradiometer (MODIS) satellite with a resolution of $1 \mathrm{~km}$ for June, July, and August of 2000-2018 was applied.

Vector data: In this study were used vector datasets of road, settlements, and other forms of land utilization such as crop field and fallow land in Bulgan province. Vector data of crop field and fallow land obtained from Mongolian national atlas (Dorjgotov, 2009). The coordinates of herders' seasonal camp place taken from the 2014 field survey used in the current research spatial analysis.

\subsection{Method}

Two types of research methods, time series analysis, and integrated assessment were used. In assessing the land degradation used three indices as the mean value of the aridity index $(\mathrm{AI})$, the change and trend of NDVI and RUE for a given period, and the Human Impact Index. Firstly, estimated spatial effects on land degradation of those three indices. And then evaluated the degree of land degradation of each index and generated an integrated map of degradation.

Temporal analysis: For spatial-temporal analysis used a spatial distribution map of AI, NDVI, and RUE. The AI is a determinant factor of climate, spatial analysis was conducted using mean value AI for the period 2000-2018. However, the percentage of average annual change in NDVI and RUE for the given period was calculated by the following formula (1):

$$
\% \text { change }=\frac{\sum_{i=2}^{n}\left(\frac{\text { Ind }_{i}}{\text { Ind }_{\text {baseline }}}-1\right) * 100 \%}{n-1}
$$

where $\quad \operatorname{Ind}_{\mathrm{i}}=$ used indicator

$\mathrm{n}=$ the number of years or indicates of data length $(\mathrm{i}=2$, ....n)

Ind $_{\text {baseline }}=$ a value at the base year for the calculation of each indicator

In this study, 2000 years is used as the base year for the calculation of each indicator. The aforementioned formula calculates where the indicator is declining or increasing over a given period compared to 2000 year and identifies areas of degradation. A positive value of the index defined by the above formula indicates an upward trend, and a negative value indicates a downward trend.

Approach for integrated degradation assessment: For spatialtemporal analysis used a spatial distribution map of AI, NDVI, and RUE. The AI is a determinant factor of climate, spatial analysis was conducted using mean value AI for the period 20002018. However, the percentage of average annual change in NDVI and RUE for the given period was calculated by the following formula (2):

$$
I A=A I+N D V I+R U E+H I I,
$$

where $\quad I A=$ integrated assessment

NDVI $=$ normalized difference vegetation index

RUE $=$ rain use efficiency

$\mathrm{HII}=$ human impact index

In this study, the assessment was based on the following criteria, considering that the level of degradation indicates the intensity of desertification. Herein, 0-no land degradation; 1-slight land degradation; 2-moderate land degradation; 3-severe land degradation.

Aridity index (AI): De Martonne formula was applied to calculate the AI of each year using the mean air temperature and total precipitation data of June, July, and August of 2000-2018, taken from meteorological observation stations (Lungu et al, 2011; Maliva and Missimer, 2012).

$$
I=\frac{P}{\left(T_{m}+10\right)},
$$

where $\quad \mathrm{P}=$ monthly the total precipitation

$\mathrm{T}_{\mathrm{m}}=$ monthly mean air temperature

According to the definition by LADA, AI is a numerical indicator for measuring the rate of aridity of a certain region (Nachtergaele et al, 2008). Moreover, it is one of the indicators that determine soil moisture content. Soil moisture significantly affects plant growth and spread, soil microbiology process, soil erosion and wind erosion, and soil characteristics and serves as an integral part of land degradation evaluation in arid regions.

Normalized difference vegetation index (NDVI): NDVI is a normalized value of vegetation cover based on spectral characteristics of green plants that are highly absorbent in the visible red spectrum, whereas highly reflective in the nearinfrared spectrum. NDVI is a suitable product for detecting land degradation and conducting time-series analysis (Bai and Dent, 2006; Spruce et al, 2011). NDVI is a suitable product conducting time-series analysis for detecting land degradation (Spruce et al, 2011; Nachtergaele et al, 2008; Bai and Dent, 2006). Determining vegetation index by remote sensing data means identification of the highest potential of vegetation intensity, taking into account the land condition and precipitation (Evans and Geerken, 2004). Application of this index is preferred in circumstances where 50 or more percent of the land is covered by vegetation, while the lower the vegetation coverage, the radiation of barren land prevails in the data transferred to the satellite (Nachtergaele et al, 2008). Long-term and continuous decrease of vegetation index indicates desertification process. Thus, determining the trend over the given period by conducting temporal analysis allows the best indicator for detecting and evaluating degradation.

Rain use efficiency (RUE): RUE is ratio of NDVI to precipitation (Bai et al, 2005). and shall be determined using the below formula (4).

$$
R U E=\frac{N D V I_{\text {summer }}}{R_{\text {summer }}},
$$

where $\quad \mathrm{NDVI}_{\text {summer }}=$ sum value of NDVI of June, July, and August for the given year $\mathrm{R}_{\text {summer }}=$ total precipitation of June, July, and August for the given year

In other words, it may be interpreted as an adequate amount of precipitation necessary for the growth of plants. Moreover, the correlation between biomass and precipitation is considered to be capable of indicating the impact of a human-induced activity on land degradation (Bai and Dent, 2006).

Human influence index: In addition to natural factors, humaninduced activities strongly affect the land degradation process. It is evaluated by the change in land utilization. Pastoral farming is the main contributing factor for land degradation and desertification, pasture land covers large areas. Overgrazing becomes a significant driver for desertification while causing land degradation being evolved due to the reduction of vegetation species and changes in soil mechanical components. Therefore, for detecting pasture utilization area used season camps of herders. The impact of human-induced activities was estimated using the Sanderson method who developed in 2002 (Woolmer et al, 2008). In total, 6 vector datasets were used for assessing the human impact index such as the density of seasonal camps (summer and winter camps) of herder households, crop fields, 
fallow land, state-level, and local roads and settlement areas. Spatial mapping of human factors on land degradation has been developed by assessing the human influence by scores between 0 and 3. Herein, 0-no influence, 1-low influence, 2-moderate influence, 3-high influence. The winter and spring camp locations, where herders tend to stay for an extended period, were included in the calculation and evaluated by their density per 1.0 $\mathrm{km}^{2}$ (Table 1).

\begin{tabular}{lc}
\hline Density & $\begin{array}{c}\text { Degree of degradation } \\
\text { level by score }\end{array}$ \\
\hline $0-0.034$ & 0 \\
$0.0341-0.1$ & 1 \\
$0.11-0.17$ & 2 \\
$0.171-0.32$ & 3 \\
\hline
\end{tabular}

Table 1. The number of winter and spring camp locations per $1.0 \mathrm{~km}^{2}$.

The crop field was rated by 3 points, the hay area was rated by 1 point, and the rest of the areas were rated by 0-3 points, by ordering by their rate of impact, creating spatial zoning at a certain distance. The area within $5 \mathrm{~km}$ from the province center was the most influential and rated by 3 points, the area within 5$10 \mathrm{~km}$ by 1 point, and the area within $5 \mathrm{~km}$ from soum center by 1 point. The road impacts are calculated as shown in the table below (Table 2) (Higginbottom and Symeonakis, 2014).

\begin{tabular}{lcccc}
\hline \multirow{2}{*}{ Type of road } & \multicolumn{4}{c}{ Standard scores for the corresponding class } \\
\cline { 2 - 5 } & $90 \mathrm{~m}>$ & $90-500 \mathrm{~m}$ & $500-1000 \mathrm{M}$ & $1000 \mathrm{M}<$ \\
\hline Paved road & 3 & 2 & 1 & 0 \\
Another road & 2 & 1 & 0 & 0 \\
\hline
\end{tabular}

Table 2. Distance from the road.

\section{RESULT}

\subsection{Aridity index}

When estimating the aridity index at the Bulgan station on the study site using the De Martonne approach, the area is defined as arid and semi-arid and less humid according to Martonne's climate classification (Lungu et al, 2011). As mentioned earlier, this circumstance adversely impacts the soil's microbiological process and further accelerates drought. Aridity index dynamics indicate that aridity tends to decline slightly over the last 19 years (Figure 3).

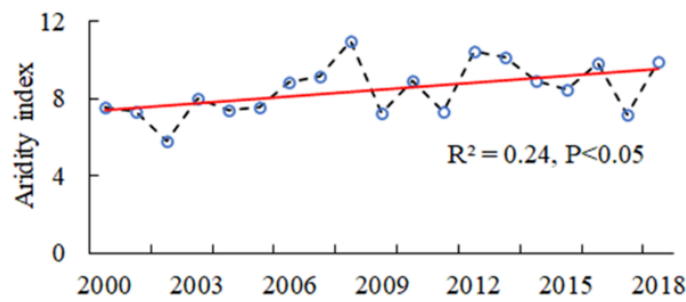

Figure 3. Estimated aridity index of De Martonne using Bulgan Metrological station data for the period 2000-2018.

Spatial distribution of the last 19 years' average aridity shows that the southern part of the study area, the arid steppe zone, is experiencing drought and land degradation and exposed to the highest risk of desertification (Figure 4).

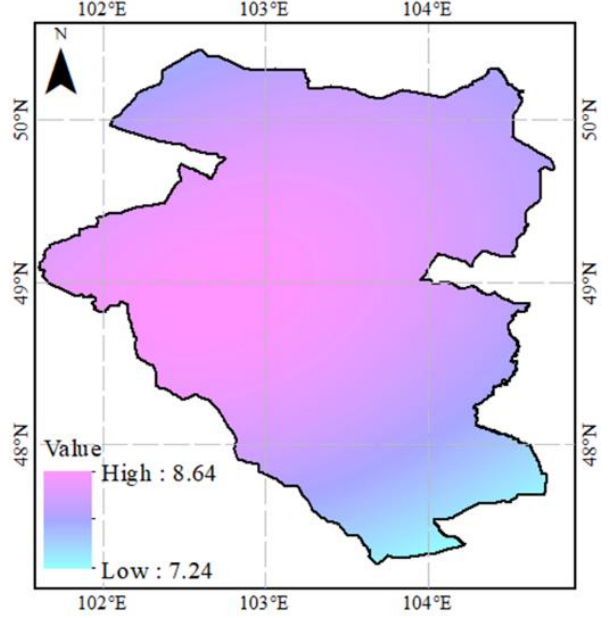

Figure 4. Spatial distribution map of aridity index for the period.

\subsection{Percentage of change in NDVI}

The estimation of the mean dynamics of 49221 points with the resolution of $1000 \mathrm{~m}$ over the research area during the study period evidences the trend of increase (Figure 5). When calculating the NDVI variation in the study area at each pixel for the period $2000-2018,76.47 \%$ of the total pixels were positive or increasing and $23.53 \%$ was negative or decreasing (Figure 6).

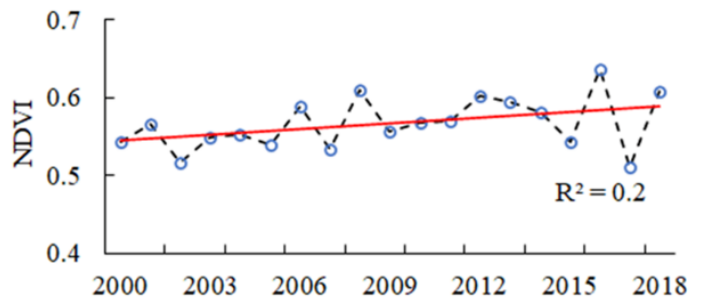

Figure 5. Variation of NDVI (June, July, and August of 20002018).

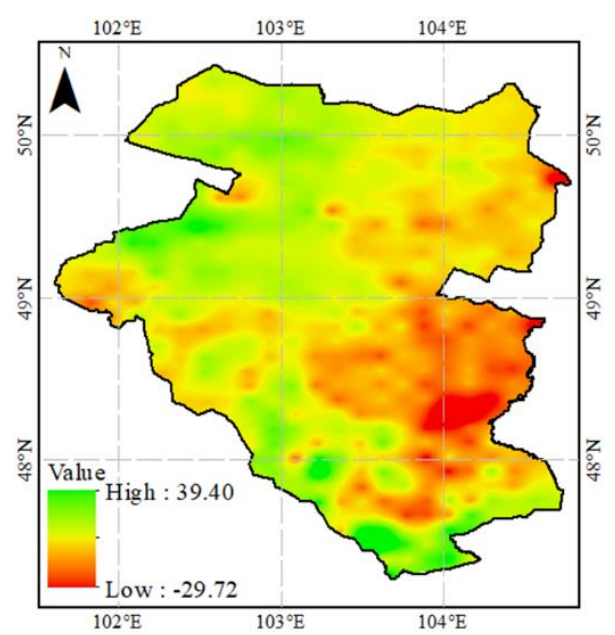

Figure 6. Percentage of average annual change in NDVI (June, July, and August of 2000-2018).

As shown in the figure, the NDVI value for the south eastern part of the region declined year by year with a minimum of $29.72 \%$ during the past 19 years compared to 2000 , and such areas are experiencing land degradation, whereas the northern and western part showed a positive trend, with NDVI values increasing with a maximum of $39.40 \%$. Here, vegetation cover growth does not 
imply that there is no degradation. It should be cross-checked and confirmed by field measurement of plant species.

\subsection{Percentage of change in RUE}

RUE is a parameter indicating the influence of precipitation fluctuation on biomass products. The estimation of the mean dynamics of 49221 points with the resolution of $1000 \mathrm{~m}$ over the research area during the study period evidences the trend of decrease (Figure 7).

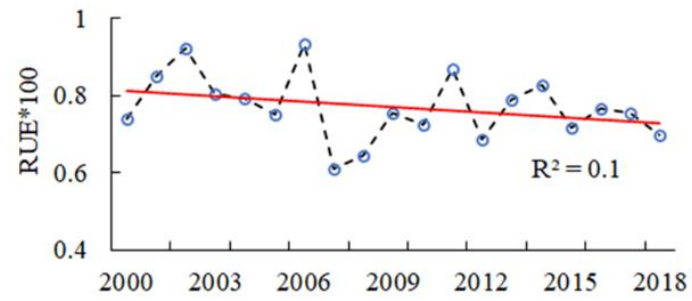

Figure 7. Variation of RUE (June, July, and August of 20002018).

A positive trend of RUE indicates land improvement, whereas a negative trend indicates degradation (Figure 8). As shown in the figure, the positive trend was identified across the northern part the taiga and forest-steppe region, whereas a negative trend was identified across the west and south part. According to the variation on each pixel location across the entire survey area, $48.47 \%$ were positive or increased with a maximum of $139.88 \%$, and $51.53 \%$ were negative or decreased with a minimum of $51.67 \%$.

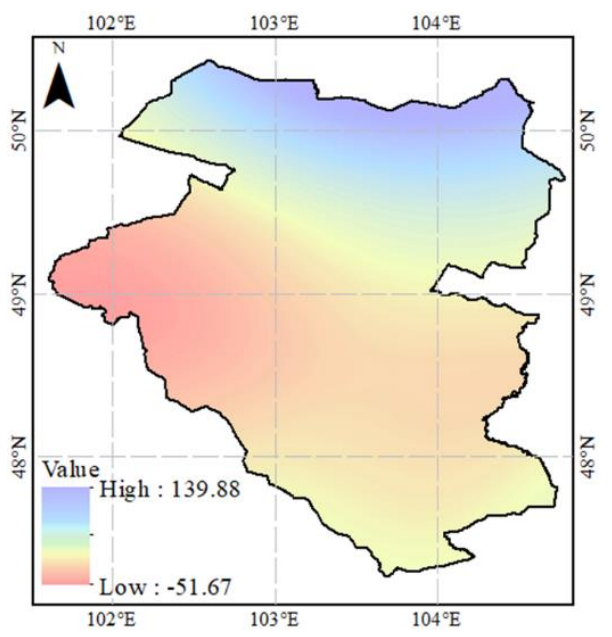

Figure 8. Percentage of average annual change in RUE (June, July, and August of 2000-2018).

\subsection{Human activity impact}

A spatial distribution map of the human factor index is developed (Figure 9). As shown in the figure three indicators were overlaid in the given survey area. The most overlaid areas include pasturelands and crop fields in the vicinity of province and soum centre, and the share of the entire overlaid distribution indicates that the grazing area has a significant impact. According to the share expressed by pixel value, the area with no human impact is $24.3 \%$ (pixel value 0), and the area impacted by some extent is $75.7 \%$ (pixel value 1-10), which might be vulnerable to degradation.

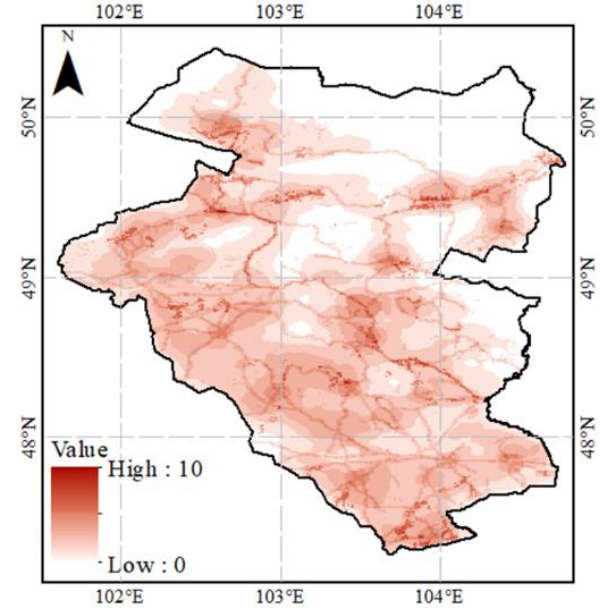

Figure 9. Spatial distribution of Human activity impact.

\subsection{Integrated assessment of land degradation}

The issue of vital importance is the diligent and correct classification of the selected indicators against the degree of land degradation. The integrated map of land degradation and desertification was developed using four indicators such as AI, NDVI, RUE and HII (Figure 10). As can be seen from the figure above, most of the non-degraded land is covered by forest. When calculating the percentage of pixels corresponding to the degree of degradation and desertification shown in the integrated map, $27.22 \%$ total pixels of the survey area is no degrade, $34.04 \%$ were slightly degraded, and $32.38 \%$ were moderately degraded, and $6.37 \%$ severely degraded. According to the integrated assessment, $72.78 \%$ of the entire area is affected by land degradation.

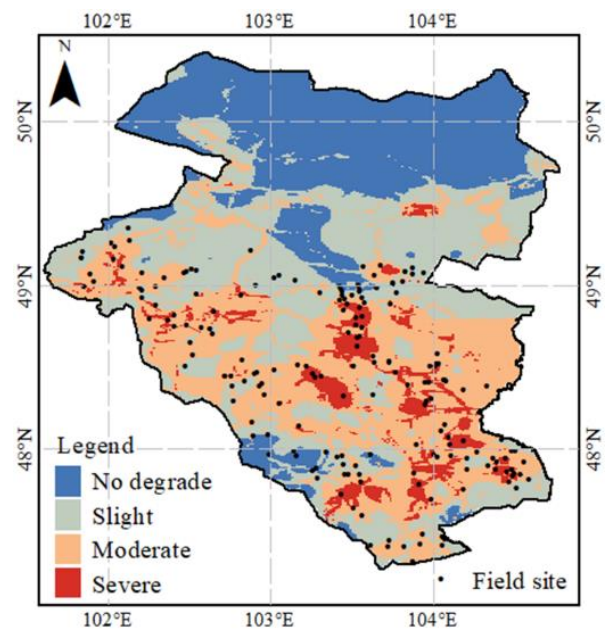

Figure 10. An integrated map of land degradation for the period 2000-2018 with field-measured biomass data.

\subsection{Accuracy assessment}

In order to assessment of accuracy, we used field-survey vegetation data. Field measurement of vegetation cover was conducted in 2018. Vegetation sample has taken from 192 sites, the number of plant species per $1 \mathrm{~m}^{2}$ area, biomass, and percentage of plant species was calculated. During the field measurement, three levels of land degradation were determined. The status of degradation identified by field measurement is as follows: 
The vegetation canopy covers over a slightly degraded area averaged between $5.2 \%$. On average, 10-20 species of plants are observed in the per $1 \mathrm{~m}^{2}$ area.

The total biomass is $45.3-86.3 \mathrm{~g} / \mathrm{m}^{2}$. For biomass composition, it was observed that forb biomass covers $58-85 \%$ of the total biomass. The biomass of the grass is higher by $23-40 \%$. At the study sites, biomasses of carex, Fabaceae, and artemisia are lower by $1-8 \%, 1-3 \%$, and $5-10 \%$, respectively.

Vegetation canopy covers ranging from $49.0 \%$ in moderately degraded areas, and the number of species was between 10 and 15. The total biomass is $22.9-56.6 \mathrm{~g} / \mathrm{m}^{2}$. The vegetation community's composition was lower than that of the less degraded pastures. The biomass of forb and grasses decreased and the biomass of weed increased.

The vegetation composition of the highly degraded area has changed significantly compared to less and moderately degraded pastureland. Decreased in the number of some species and increase of plants of particular species (weed, which is not edible for animals and resistant to pasture land degradation) in the total biomass, has been identified. Although the sign that the percentage of vegetation canopy cover dropped to a lower level than that of low and medium degraded pastures has been identified, the canopy cover is dense $(73.2 \%)$ since the plants shortened due to the deterioration within the community. If we do not protect it, the degradation process will transit to a more severe level, and the formation of bare ground in the plant community will commence.

The results of field measurements and the number of grades of the assessed indicator at each point are shown in the below table (Table 3). Field measurements show that the land was slightly degraded at 10 points, moderately degraded at 94 points, and severely degraded at 88 points. Also, as mentioned earlier, if the vegetation canopy cover index was higher by analysis of remote sensing methods, this does not mean that the land is not degraded.

\begin{tabular}{clcc}
\hline \multirow{2}{*}{ Score } & \multirow{2}{*}{$\begin{array}{c}\text { Degree of land } \\
\text { degradation }\end{array}$} & \multicolumn{2}{c}{$\begin{array}{c}\text { Number of the pixel } \\
\text { value }\end{array}$} \\
\cline { 3 - 4 } & Field sites & IA \\
\hline 0 & No degrade & & 7 \\
1 & Slight & 10 & 52 \\
2 & Moderate & 94 & 99 \\
3 & Severe & 88 & 34 \\
\hline
\end{tabular}

Table 3. Comparison between field measurement of vegetation and estimated integrated assessment.

According to field measurements, coverage becomes denser due to the decline of community and plant shrinking processes. As can be observed from the correlation, the integrated assessment map coincides with the field measurement by a tolerance coefficient of 0.62 . This shows that the study can be used in practice.

\section{DISCUSSION}

The aridity index indicates the impacts on climate degradation, and in arid areas, the lack of soil moisture is commonly observed, which is the top factor for land degradation combined with human factors. According to the study, the southern part of the study area (arid steppe zone) is the most likely closer to the threat of land degradation. The maximum frequency of perennial declines in NDVI is highly correlated with the stages of moderate to severe land degradation levels. Therefore, when NDVI is used as a land degradation indicator, the greater the years of decline are used, the better the detection of degraded land. NDVI does not detect changes in vegetation species in degraded areas other than vegetation cover. Thus, it is recommended that field measurements of species might be used to determine the degradation of land, where NDVI is high. RUE indicates the potential of plant growth and precipitation falling in the study area positively affects plant growth. However, the perennial decline proves that biomass is not reaching the required level. In other words, it confirms that external or human-induced impact observes over the study area.

This approach, which estimates the human impact index by creating a specific spatial distribution, has made it possible to identify the most extended areas exposed to degradation. This is the optimal method for countries with pastoral farming similar to Mongolia. Pastoral farming covers a large area, and it is challenging to determine spatial scope accurately. The issue of vital importance is the diligent and correct classification of the selected indicators regarding land degradation and desertification degree. The accuracy of the integrated assessment map was reconfirmed by field vegetation measurement. The outcome of the integrated map proves that $27.22 \%$ of the total research area is not degraded, $34.04 \%$ slightly degraded, and $32.38 \%$ moderately degraded, and $6.37 \%$ severely degraded.

\section{CONCLUSION}

This study is either efficient as the compilation of natural and human factors is ensured or advantages as field vegetation measurements reconfirm it. In short, it is notable that the study has effectively correlated the remote sensing data and spatial analysis with field measurements. The reconfirmation by field measurement shows the viability and applicability of research. When the dataset of spatial-temporal for grazing is optimized, then the best result in determining the impact of human activities is ensured. Since land degradation and desertification have been assessed spatially, suitable measures might be taken for each degree of degradation. For example, measures including, fencing of degraded land, planting nutritious seeds, and allowing for natural regeneration (scheduled use of pastureland).

\section{ACKNOWLEDGEMENTS}

We thank all colleagues at the Institute of Geography and Geoecology, Mongolian Academy of Sciences who helped in this study. We would like to thank two reviewers for providing valuable feedback and suggestions.

\section{REFERENCES}

Bai, Z. G., Dent, D. L., 2006. Global assessment of land degradation and improvement: Pilot study in Kenya. Report 2006/01, ISRIC-World Soil Information, Wageningen.

Bai, Z.G., Dent, D.L., Schaepman, M.E., 2005. Quantitative global assessment of land degradation and improvement: Pilot study in North China. Report 2005/6, ISRIC-World Soil Information, Wageningen.

Chattopadhyay, S., Edwards, D.R., 2016. Long-Term Trend Analysis of Precipitation and Air Temperature for Kentucky, United States. Climate, 4(10).

https://doi.org/10.3390/cli4010010.

Dash, D., 2010: Landscape-ecological issues of Mongolia. Press of Munkhiin Useg. Ulaanbaatar, Mongolia.

Dorjgotov, D., 2009: National Atlas of Mongolia. Ulaanbaatar, Institute of Geography. 
Evans, J., Geerken, R., 2004. Discrimination between climate and human-induced dryland degradation. Journal of arid environments, 57(4), 535-554.

Higginbottom, T. P., Symeonakis, E., 2014. Assessing land degradation and desertification using vegetation index data: Current frameworks and future directions. Remote Sensing, 6(10), 9552-9575.

Institute of Geo-botany and Institute of Geography (IGB\&IG), Mongolian Academy of Sciences (MAS)., 2014. Pasture vegetation and soil degradation in Bulgan province and influencing factors. Report, Ulaanbaatar, Mongolia.

Kellner, K., Risoli, C., Metz, M., 2011. Terminal evaluation of the UNEP/FAO/GEF project: Land Degradation Assessment in Drylands (LADA). United Nation Environment Programme.

Kimura. R., 2018. Global distribution of degraded land area based on dust erodibility determined from satellite data. International Journal of Remote Sensing, 39:18, 58595871 .

Lungu, M., Panaitescu, L., Nita, S., 2011. Aridity, climatic risk phenomenon in Dobrudja. Present Environment and Sustainable Development 5 (1), 179-190.

Maliva, R., Missimer, T., 2012. Arid lands water evaluation and management. Springer Science \& Business Media.

Ministry of Environment and Tourism of Mongolia (METM)., 2014. State of the environment report Mongolia, 2013-2014. http:www.eic.mn/DLDbase/.../4/20150616_6685_4.pdf

Munkhdulam, O., Sainbayar, D., 2012. Assessment of land degradation Taats river basin of Mongolia using satellite images and socio-economic data. Proceedings of Workshop called Mini Project, Geo-informatics Center, Asian Institute Technology, Bangkok, Thailand. http://geoinfo.ait.ac.th/assessment-of-landdegradation-in-taats-river-basin-of-mongolia-using-satelliteimages-and-socio-economic-data/.

Nachtergaele F.O., Licona-Manzur C., 2008. The Land Degradation Assessment in Drylands (LADA) Project: Reflections on Indicators for Land Degradation Assessment. In: Lee C., Schaaf T. (eds) The Future of Drylands. Springer, Dordrecht. https://doi.org/10.1007/978-1-4020-6970-3_33.

National Program to Combat Desertification of Mongolia (NPCDM)., 2010. http://www.legalinfo.mn. (21 April 2021)

Natsagdorj, L., 2009: Desertification and climate change. Press of Bambi foundation, Ulaanbaatar, Mongolia.

Otgonbayar, M., Atzberger, C., Chambers, J., Damdinsuren, A., 2019a. Mapping pasture biomass in Mongolia using partial least squares, random forest regression and Landsat 8 imagery. International Journal of Remote Sensing, 40(8), 3204-3226.

Otgonbayar, M., Atzberger, C., Mattiuzzi, M., Erdenedalai, A., $2019 \mathrm{~b}$. Estimation of climatologies of average monthly air temperature over mongolia using MODIS land surface temperature (LST) time series and machine learning techniques. Remote Sensing, 11(21), 2588.
Spruce, J. P., Sader, S., Ryan, R. E., Smoot, J., Kuper, P., Ross, K., Prados, D., Russell, J., Gasser, G., McKellip, R., Hargrove, W., 2011. Assessment of MODIS NDVI time series data products for detecting forest defoliation by gypsy moth outbreaks. Remote sensing of environment, 115(2), 427-437.

Sterk, G., Stoorvogel, JJ., 2020. Desertification-Scientific Versus Political Realities. Land, 9(5):156. https://doi.org/10.3390/land9050156.

Touseef, M., Chen, L., Yang, K., Chen, Y., 2020. Long-Term Rainfall Trends and Future Projections over Xijiang River Basin, China. Advances in Meteorology, vol. 2020, Article ID 6852148, 18 pages. https://doi.org/10.1155/2020/6852148.

Tsogtbaatar, J., Khudulmur, S., 2014: Desertification atlas of Mongolia. Ulaanbaatar, Mongolia.

Woolmer, G., Trombulak, S. C., Ray, J. C., Doran, P. J., Anderson, M. G., Baldwin, R. F., Morgan, A., Sanderson, E. W., 2008. Rescaling the human footprint: a tool for conservation planning at an ecoregional scale. Landscape and Urban Planning, 87(1), 42-53. 